\title{
Mass-Independent Fractionation of Titanium Isotopes
}

DOI:

10.1016/j.chemphys.2020.110970

\section{Document Version}

Accepted author manuscript

Link to publication record in Manchester Research Explorer

\section{Citation for published version (APA):}

Robert, F., Reinhardt, P., \& Tartèse, R. (2020). Mass-Independent Fractionation of Titanium Isotopes. Chemical Physics, 110970. https://doi.org/10.1016/j.chemphys.2020.110970

\section{Published in:}

Chemical Physics

\section{Citing this paper}

Please note that where the full-text provided on Manchester Research Explorer is the Author Accepted Manuscript or Proof version this may differ from the final Published version. If citing, it is advised that you check and use the publisher's definitive version.

\section{General rights}

Copyright and moral rights for the publications made accessible in the Research Explorer are retained by the authors and/or other copyright owners and it is a condition of accessing publications that users recognise and abide by the legal requirements associated with these rights.

\section{Takedown policy}

If you believe that this document breaches copyright please refer to the University of Manchester's Takedown Procedures [http://man.ac.uk/04Y6Bo] or contact uml.scholarlycommunications@manchester.ac.uk providing relevant details, so we can investigate your claim.

\section{OPEN ACCESS}




\title{
Mass-Independent Fractionation of Titanium Isotopes
}

\author{
François Robert, ${ }^{1 *}$ Peter Reinhardt, ${ }^{2}$ Romain Tartèse ${ }^{3}$ \\ 1 Muséum National d'Histoire Naturelle, Institut de Minéralogie, \\ Physique des Matériaux et Cosmochimie, \\ CNRS UMR 7590, 61 rue Buffon, 75005 Paris, France. \\ ${ }^{2}$ Laboratoire de Chimie Théorique, Sorbonne Université et CNRS UMR 7616, \\ 4 place Jussieu, 75252 Paris Cedex 05, France. \\ 3 Department of Earth and Environmental Sciences, The University of Manchester, \\ Oxford Road, Manchester M13 9PL, United Kingdom
}

\footnotetext{
* Correspondence to: François Robert (francois.robert@mnhn.fr)
} 
Forty years ago, the synthesis of ozone has revealed mass-independent fractionation (MIF) of oxygen isotopes. Among the numerous published interpretations of this ozone effect, the present paper reports that a titanium MIF observed during chemical reactions in plasma can be accounted for by one of these theoretical treatments. A gaseous mixture of $\mathrm{TiCl}_{4} / \mathrm{C}_{5} \mathrm{H}_{12}$ carried in a glass tube by a continuous flow of $\mathrm{N}_{2}$ was submitted to a HF discharge. Carbonaceous grains, presumably resulting from homogeneous condensation, show radial variations in Ti concentration with isotopic variations ranging from -25 to $+125 \%$ for all ${ }^{\mathrm{m}} \mathrm{Ti} /{ }^{48} \mathrm{Ti}$ isotope ratios ( $m$ standing for masses 46, 47, 49 and 50).

It is proposed that the reduction rates by carbon radicals, of the metastable molecules formed by the isotope exchange reactions between $\mathrm{Ti}$ and $\mathrm{TiCl}_{4}$ are different if they involve distinguishable or indistinguishable isotopes. A numerical simulation reproduces the experimental isotope patterns defined by the ${ }^{\mathrm{m}} \mathrm{Ti} /{ }^{48} \mathrm{Ti}$ isotope ratios.

PACS numbers: 


\section{INTRODUCTION}

The discovery of the mass-independent isotope fractionation (MIF) of oxygen isotopes in ozone ${ }^{1-3}$ has drawn considerable theoretical and experimental interest. ${ }^{4-20}$ However, no consensus has been yet reached in the literature about the origin of MIF. Interestingly, a similar isotopic distribution of oxygen isotopes was observed fifty years ago in the refractory minerals of the carbonaceous meteorites (usually referred to as CAIs, Calcium- and Aluminum-rich inclusions). ${ }^{21}$ These minerals are regarded as the first solids condensed at 1200-1600K in the early Solar System (the so called protosolar disk ${ }^{22}$ ).

For heavier elements such as N, C, Ti, Si etc., sub-micrometer grains isolated from meteorites have shown isotopic compositions having marked departures from mass-dependent fractionation ${ }^{23-28}$ (MDF). These grains are referred to as "presolar grains" and their isotopic compositions attributed to stellar nucleosynthetic signatures. ${ }^{25}$ Note that, heavy element MIF originally found in $\mathrm{CAIs}^{29}$ were recently resolved at a much lower level of detection between planetary components. ${ }^{30-33}$ These isotopic effects are attributed to nuclear processes, i.e. to grains condensed in the envelope of dying $\operatorname{stars}^{34}$ over the age of the galaxy and having survived the gravitational collapse of the protosolar disk. See a review of these data by. ${ }^{33,35}$

The recent ozone interpretation entailed the possibility that MIF effects can be also extended to other chemical elements during oxidizing or reducing chemical reactions in plasma. ${ }^{1,36,37}$ Because these chemical conditions could be transposed to those at the origin of the presolar grains, we have developed an experiment where chemical reactions mimic those presumably responsible for the MIF effect in ozone.

Presolar grains are condensed at high temperature from their gaseous state in reducing or oxidizing conditions. Because of the difficulty to reproduce experimentally these hightemperature conditions in the laboratory, we have chosen to study the reduction of the gaseous titanium chlorides during their condensation on grains in a plasma.

The MIF effect is usually illustrated in the diagram where the 2 isotope ratios ${ }^{17} \mathrm{O} /{ }^{16} \mathrm{O}$ and ${ }^{18} \mathrm{O} /{ }^{16} \mathrm{O}$ are expressed in their $\delta$ units, that is

$$
\delta^{m} \mathrm{O}(\% 0)=\left[\frac{R_{\text {sple }}}{R_{\text {std }}}-1\right] \times 1000
$$

with $R={ }^{m} \mathrm{O} /{ }^{16} \mathrm{O}$; "sple" and "std" standing for sample and standard and $m$ for the mass numbers 17 or 18 . 
The isotopic fractionation factor $\alpha$ is defined when the standard is the reservoir from which the chemical products are formed:

$$
\delta^{m} \mathrm{O}(\%)=[\alpha-1] \times 1000
$$

In the usual theory, the mass-dependent fractionation (MDF) can be illustrated in the $\delta^{17} \mathrm{O}(\% 0)$ vs. $\delta^{18} \mathrm{O}(\% 0)$ diagram. In this 3-isotope diagram, all isotope exchange reactions at equilibrium or not - should define a linear correlation having slope of $0.52 .^{38-41}$ At a first approximation, such a behavior is caused by the difference in mass between ${ }^{18} \mathrm{O}$ and ${ }^{16} \mathrm{O}$ which is twice that between ${ }^{17} \mathrm{O}$ and ${ }^{16} \mathrm{O}$. This property is common to all chemical elements and observed in natural or experimental situations, in liquid or solid phase reactions. On the contrary, MIF effects are characterized by a slope of $\approx 1.0$ in the $\delta^{17} \mathrm{O}(\% 0)$ versus $\delta^{18} \mathrm{O}(\% 0)$ diagram.

In addition to the fact that MIF effects for oxygen isotopes are not restricted to ozone (they have been observed in several atmospheric molecules ${ }^{42}$ ), recent experimental evidence suggest that they can also be extended to other elements. ${ }^{43}$ For example, (i) the synthesis of ammonia in the gas phase via the photochemical dissociation of $\mathrm{N}_{2}$ - has also yielded $a^{15} \mathrm{~N}$ selection in much larger excess than predicted by the classical isotope fractionation theory ${ }^{44}$ (ii) the condensation of organic matter from a plasma of $\mathrm{CH}_{4}$ have generated an unexpectedly large heterogeneous distribution of hydrogen isotopes ${ }^{45}$ or (iii) several effects where isotopes are selected by their nuclear spins and nuclear magnetic moments. ${ }^{46-48}$ A MIF for sulfur isotopes has also been widely observed in the oldest sedimentary rocks on Earth and is interpreted as a signature of ancient atmospheric chemistry. ${ }^{49}$ As a whole, these experiments and natural observations have revealed the importance of radical chemistry triggered by molecular dissociation.

The MIF effect in ozone is characterized by two phenomenological parameters: $\alpha$ and $\eta$, the MDF and MIF factors, respectively. Oxygen having only 3 stable isotopes, it is not possible to identify individually $\alpha$ and $\eta$ since the overall isotopic fractionation results from the product $\alpha \times \eta$. Titanium having more than 3 isotopes, the diagram $\delta^{m}$ Ti versus $m(m$ being the masses 46, 47, 48, 49 and 50) allows to remove this indetermination. A heuristic and purposely simplified example is given in Figure 1 where it can be observed that $\alpha$ and $\eta$ can be defined for elements having 4 isotopes or more. Hence the choice of titanium (5 isotopes) in the present experimental study. 
Beside their possible astronomical implications, ${ }^{50}$ our results reveal that most chemical elements are likely to show MIF effects similar to those observed in ozone. Since MIF is not understood on a quantum-mechanical basis, it seems important to document experimentally these chemical systems. This is also the purpose of the present study.

\section{EXPERIMENTAL METHODS}

\section{A. Plasma}

The formation of titanium nanoparticles from rapidly quenched plasma mixtures has been experimentally observed and we follow these studies. ${ }^{51,56}$ According to one of the nu-

merous interpretation proposed for ozone, ${ }^{57,58}$ MIF effects take place when a fraction of the metastable molecules (noted $\left[\mathrm{Ti}_{x} \mathrm{Cl}_{y}\right]^{*}$ ) involved in an isotopic exchange is retrieved by a chemical reaction. Contrary to thermal gases, in plasma, highly reactive radicals greatly favor isotope exchange reactions. Our aim in using a plasma mixture of $\mathrm{TiCl}_{4} / \mathrm{C}_{5} \mathrm{H}_{12}$ (pentane) was to trigger the isotope exchange between $\mathrm{Ti}$ and $\mathrm{TiCl}_{4}$ followed by the retrieval of the metastable $\left[\mathrm{Cl}_{2} \mathrm{Ti}-\mathrm{TiCl}_{2}\right]^{*}$ via its reduction with the carbon radicals resulting from the dissociation of $\mathrm{C}_{5} \mathrm{H}_{12}\left(\mathrm{C}_{x} \mathrm{H}_{y}^{\bullet}\right)^{45}$ The formation of organic Ti-rich films and grains was achieved using a hyperfrequence (HF) excitation, forming a "plasma state". ${ }^{59,60}$ Experimental conditions were reported by. ${ }^{45,50}$

\section{B. Morphological structures of the deposits}

Organic deposits in the plasma are formed by two main paths: (i) homogeneous coagulation of grains, which generally generates sub-micrometric particles, and (ii) heterogeneous growth of organic films due to a direct gas/solid condensation on the cold glass walls $\left(60^{\circ} \mathrm{C}\right)$ of the plasma reactor.

Organic matter $(\mathrm{OM})$ was deposited either on the glass walls or on silicon wafers as 10-100 nm thick films (cf. Supplementary Material) located before, right at the center, and after the discharge. The molecular structure of this OM was established in another study. ${ }^{61}$ It consists of 1 to 4 aromatic ring families linked by short aliphatic chains. This structure likely results from the progressive addition of $\mathrm{C}_{x} \mathrm{H}_{y}^{\bullet}$ radicals causing a progressive chain elongation, its closure in the gas phase and its condensation as aromatic moieties. ${ }^{62}$ The 
analytical technique (GCMS) used does not allow to identify the possible speciation of Ti: metallic Ti, Ti chlorides or Ti as a heteroelement.

On the silicon wafers, organic grains up to $2 \mu \mathrm{m}$ in diameter were sitting on top of the amorphous OM layer. Elemental analyses show that both OM films and carbonaceous grains are Ti-rich. The spatial distribution of titanium isotope ratios in one of these grains was analyzed and is discussed in details in this paper. Bulk analyses on several other but smaller grains are reported in Ref. 50.

\section{Isotopic analyses}

The Ti isotope composition of experimental products was measured using the CAMECA NanoSIMS 50L at The University of Manchester. This instrument is an ion microprobe optimizing SIMS analysis for high spatial resolution. The surface of the solid sample is sputtered with a focused primary ion beam and the secondary ions ejected from the sample surface are collected by mass spectrometry. Isotope ratios were recorded in a rastered area of $3 \times 3 \mu \mathrm{m}$ in size. A grain was analyzed in details; data are reported in Table I where ${ }^{12} \mathrm{C}$, ${ }^{35} \mathrm{Cl}$ and ${ }^{48} \mathrm{Ti}$ ion intensities are given in counts per second and the ion image have been divided in 6 zones based on ${ }^{48} \mathrm{Ti}$ threshold. In this image made of $256 \times 256$ pixels, isotopic variations were resolvable with a spatial resolution of $\approx 200 \mathrm{~nm}$ and with an analytical depth of $\approx 10 \mathrm{~nm}$. The grain ( $\approx 2 \mu \mathrm{m}$ in diameter) is sitting at the center in the ion image (cf. Fig. 1SM, Supplementary Material).

The statistical error $( \pm 1$ sigma $)$ on isotope ratio is defined as $1 / \sqrt{n}$ with $n$ the total number of ions detected by the mass spectrometer. Analytical conditions are reported in Ref. 50 and in Supplementary Material. The isotopic data (Table I) for the grain are reported in the $\delta^{m} \mathrm{Ti}(\% 0)$ units with $m$ standing for the mass numbers 46 to 50 .

A terrestrial organic synthetic powder (cyclopentadienyl-titanium dichloride) was used as a standard. It has been verified by mass spectrometry (ICPMS ${ }^{63}$ ) that the standard has the natural isotopic abundance of $\mathrm{Ti}$ i.e. $\delta^{m} \mathrm{Ti}=0 \pm 0.1 \%$ at all masses. The corresponding isotopic ratios are 0.1119, 0.1009, 0.07339, 0.07027 for ${ }^{46} \mathrm{Ti} /{ }^{48} \mathrm{Ti},{ }^{47} \mathrm{Ti} /{ }^{48} \mathrm{Ti},{ }^{49} \mathrm{Ti} /{ }^{48} \mathrm{Ti}$, ${ }^{50} \mathrm{Ti} /{ }^{48} \mathrm{Ti}$, respectively.

No analytical isotope effect was detectable at the level of our precision, i.e. for reproducibilities of $\pm 5.5, \pm 4.8, \pm 5.1$ and $\pm 5.7 \%$ for $\delta^{46} \mathrm{Ti}, \delta^{47} \mathrm{Ti}, \delta^{49} \mathrm{Ti}$ and $\delta^{50} \mathrm{Ti}$, respectively 
( $2 \sigma$ errors, 42 analyses bracketing the samples).

\section{RESULTS}

A $50 \mathrm{~nm}$ layer of organic matter was deposited on the silicon wafer located downstream of the plasma. Numerous carbonaceous grains were observed deposited on top of this layer (cf. the figure in the Supplementary Material). Their bulk analyses reveal a lower Ti con-

centration than the organic layer but with systematic enrichments or depletions in ${ }^{48} \mathrm{Ti}$ by several per cents. ${ }^{50}$ In the grains, the ${ }^{46} \mathrm{Ti},{ }^{47} \mathrm{Ti},{ }^{49} \mathrm{Ti},{ }^{50} \mathrm{Ti}$ isotopes are not fractionated relative to each other (Table I).

The data for a grain analyzed in detail are also reported in Fig. 2. Error bars combine the statistical errors and the reproducibilities determined on the standard $(\approx \pm 6 \%$ at all masses).

Positive and negative MIF effects were observed at all masses and for all concentration ranges. The $\delta^{m} \mathrm{Ti}$ increases from $-250 \%$ to $+1250 \%$ while the Ti concentration decreases from the border to the core of the grains. At the image bulk scale, the mass balance is partially achieved (i.e. $\delta^{m} \operatorname{Ti}(\%) \approx 0$ ) with a residual fractionation of $+33 \%,+61 \%$, $+62 \%$ o and $+92 \%$ for $m=46,47,49$ and 50, respectively. In the diagram shown in Fig. 2 all types of known MDF fractionations in natural samples are limited to a few \%o with strictly linear correlations. The slope of these linear correlations gives the MDF factor expressed per mass unit (cf. Fig. 1). Within the precision of the data, no MDF effect is observable between the different patterns.

Without a proper chemical calibration (not done in the present study) elemental ionic analyses with the NanoSims are not quantitative because the emissivity of each element varies with its electronic affinity and with the chemistry of its embedding matrix. Some qualitative information can nevertheless be extracted from our analyses. In the synthetic standard the $\mathrm{Ti} / \mathrm{C}$ and $\mathrm{Ti} / \mathrm{Cl}$ atomic ratios are 0.1 and 0.5 , respectively. The corresponding ${ }^{48} \mathrm{Ti}^{+} /{ }^{12} \mathrm{C}^{+}$and ${ }^{48} \mathrm{Ti}^{+} /{ }^{35} \mathrm{Cl}^{+}$ionic ratios are $(8.7 \pm 1.5) \times 10^{2}$ and $(4.1 \pm 2.1) \times 10^{2}$, respectively.

In the grain, the ${ }^{48} \mathrm{Ti}^{+} /{ }^{35} \mathrm{Cl}^{+}$varies from the surface $\left(4 \times 10^{3}\right)$ to the core $\left(3 \times 10^{2}\right)$ with no significant variation of the ${ }^{48} \mathrm{Ti}^{+} /{ }^{12} \mathrm{C}^{+}$ratio $\left(\approx 2 \times 10^{3}\right)$. Thus, the core has a stoichiometry close to $\mathrm{TiCl}_{4 \pm 2}$ while the surface has an excess of $\mathrm{Ti}$ atoms. The bulk grain has a stoichiometry close to $\mathrm{TiC}_{5 \pm 2}$ (i.e. an atomic ratio titanium to carbon twice that of 
the synthetic standard).

\section{INTERPRETATION: ORIGIN AND FORMALISM OF MIF EFFECTS}

Several questions are raised by these results, namely: (i) what is the physical origin of MIF, (ii) what are the chemical reactions involved in the effect, and (iii) what mechanism accounts for the radial distribution of titanium isotopes in grains.

\section{A. Origin of the effect}

As observed for the isotopomers of ozone (up to $+500 \%$ for ${ }^{16} \mathrm{O}^{18} \mathrm{O}^{18} \mathrm{O}$ ) ${ }^{9}$ ), the isotopic fractionation for Ti MIF is 2-3 orders of magnitude (in \%o) higher than generally measured in natural or experimental samples. ${ }^{41}$

Two classes of interpretations for the MIF effect in ozone have been proposed in the literature. They involve either (i) the differences in the isotopic exchange rates caused by differences in the symmetry of the metastable molecule ${ }^{10-12,15,16}$ or (ii) the higher degree of symmetry of scattering cross sections involving indistinguishable isotopes relative to those involving distinguishable isotopes. ${ }^{57,58}$ Both effects yield the same formalism for the MIF model developed in this article. Note that magnetic isotope effects ${ }^{46,47}$ (MIE) also yield mass-independent fractionation. The present results allow to reject the hypothesis of a nuclear spin control on the chemical reaction because the 4 isotopes ${ }^{46} \mathrm{Ti},{ }^{47} \mathrm{Ti},{ }^{49} \mathrm{Ti}$ and ${ }^{50} \mathrm{Ti}$ show the same MIF factor although ${ }^{46} \mathrm{Ti},{ }^{48} \mathrm{Ti}$ and ${ }^{50} \mathrm{Ti}$ have zero nuclear spin.

We now summarize the interpretation ${ }^{57,58}$ calling upon the property of the scattering cross sections involving indistinguishable isotopes.

The formation of TiTiM goes through a formation of a metastable complex $\left[\mathrm{Ti}_{2} \mathrm{M}\right]^{*}(\mathrm{M}$ standing for a chemical bound) with an associated average lifetime $\bar{\tau}$

$$
\mathrm{TiM}+\mathrm{Ti} \longrightarrow\left[\mathrm{Ti}_{2} \mathrm{M}\right]^{*} \longrightarrow \mathrm{Ti}+\mathrm{TiM}
$$

If isotopes are distinguishable as in classical scattering processes, this average lifetime is

$$
\bar{\tau}=\frac{\int_{\tau_{\min }}^{\infty} \tau f(\tau) d \tau}{\int_{\tau_{\min }}^{\infty} f(\tau) d \tau}
$$

with some distribution functions $f(\tau)$, and a minimum lifetime $\tau_{\min }$. Beyond this minimum

lifetime $\tau_{\min },\left[\mathrm{Ti}_{2} \mathrm{M}\right]^{*}$ is available for a subsequent chemical reaction; below this threshold, 
$\left[\mathrm{Ti}_{2} \mathrm{M}\right]^{*}$ spontaneously dissociates as in reaction (1). We now look at lifetimes of a complex $\left[\mathrm{Ti}_{2} \mathrm{M}\right]^{*}$ longer than $\tau_{\min }$.

We may split $\bar{\tau}$ in two parts, one arising from scattering with isotope exchange (R), and one without (NR):

$$
\bar{\tau}=y \bar{\tau}_{\mathrm{R}}+(1-y) \bar{\tau}_{\mathrm{NR}}
$$

Thus:

$$
\bar{\tau}_{\mathrm{R}}=\frac{\int_{\min _{\min }}^{\infty} \tau f_{\mathrm{R}}(\tau) d \tau}{\int_{\tau_{\min }}^{\infty} f_{\mathrm{R}}(\tau) d \tau}
$$

and, consequently,

$$
y=\frac{\int_{\tau_{\min }}^{\infty} f_{\mathrm{R}}(\tau) d \tau}{\int_{\tau_{\min }}^{\infty}\left(f_{\mathrm{R}}(\tau)+f_{\mathrm{NR}}(\tau)\right) d \tau}
$$

with a corresponding construction of $\tau_{\mathrm{NR}}$. From (classical) scattering simulation we may obtain the distribution function $f(\tau)$ in its two parts, $f_{\mathrm{R}}$ and $f_{\mathrm{NR}}$. Suppose further that we can express the dimensionless $y$ as:

$$
y=\frac{Y_{\mathrm{R}} P_{\mathrm{R}}}{Y_{\mathrm{R}} P_{\mathrm{R}}+Y_{\mathrm{NR}} P_{\mathrm{NR}}}
$$

with a "probability" $P$ and a "relative abundance" $Y$, both positive and $Y$ obeying $Y_{\mathrm{R}}+$ $Y_{\mathrm{NR}}=1 . Y_{\mathrm{R}}$ then stands for the fraction of exchange involved in the formation of $\left[\mathrm{Ti}_{2} \mathrm{M}\right]^{*}$ :

$$
Y_{\mathrm{R}}=\frac{\int_{0}^{\infty} f_{\mathrm{R}}(\tau) d \tau}{\int_{0}^{\infty}\left(f_{\mathrm{R}}(\tau)+f_{\mathrm{NR}}(\tau)\right) d \tau}
$$

while $y$ stands for the fraction of exchange reactions taking place during the chemical reaction of $\left[\mathrm{Ti}_{2} \mathrm{M}\right]^{*} .{ }^{65}$

If we have now indistinguishable isotopes, we cannot assign any more $R$ and $N R$, but should deal with a (quantum-mechanical) superposition of both processes. The simplest modification of the classical scattering processes is to average $P_{\mathrm{R}}$ and $P_{\mathrm{NR}}$ to a common value which then yields $y=Y_{\mathrm{R}}$. The average lifetime $\tau_{\text {indist. }}$ for $\left[\mathrm{Ti}_{2} \mathrm{M}\right]^{*}$ formed by reactions between indistinguishable isotopes becomes:

$$
\begin{aligned}
\bar{\tau}_{\text {indist. }} & =Y_{\mathrm{R}} \bar{\tau}_{\mathrm{R}}+\left(1-Y_{\mathrm{R}}\right) \bar{\tau}_{\mathrm{NR}} \\
& =\left(1-Y_{\mathrm{NR}}\right) \bar{\tau}_{\mathrm{R}}+Y_{\mathrm{NR}} \overline{\bar{\tau}}_{\mathrm{NR}}
\end{aligned}
$$

showing the symmetry of the two different $\mathrm{R}$ and NR processes - we may have started equally well by defining $Y_{\mathrm{NR}}$. 
The two processes (between dist- and indistinguishable isotopes) are schematically compared in Figure 3.

If masses of the isotopes were all equal, we obtain from the reaction rates the massindependent fractionation factor as the dist- to indistinguishable lifetime ratio:

$$
\eta=\frac{\bar{\tau}}{\bar{\tau}_{\text {indist. }}}
$$

which we apply as well here, bearing in mind the approximation. However, in the case of

ozone a reasonable $\tau_{\min }$ had been determined which, inserted in the described procedure, led to most of the experimental results.

As discussed in the next Section IV B, in the case of $\mathrm{TiCl}_{4}$, we should expect a value of $\eta$ of the order of 4 in order to reproduce the maximum MIF effect observed in the core of the grain. From the insertion reaction of $\mathrm{Ti}$ into $\mathrm{TiCl}_{4}$ this may be a reasonable value, as the isotope exchange via the intermediate formation of $\mathrm{Cl}_{2} \mathrm{Ti}-\mathrm{TiCl}_{2}$ is quite difficult with respect to the formation of associative complexes $\mathrm{Ti}-\left(\mathrm{TiCl}_{4}\right)$ and since the intermediate complex will probably be formed in an excited triplet state $\left(\mathrm{Ti}\left({ }^{3} F\right.\right.$, triplet $)+\mathrm{TiCl}_{4}$ (singulet) $)$, and not in its singlet ground state.

\section{B. Chemical reactions at the origin of MIFs}

The MIF effect observed here is attributed to the reduction of the metastable complex $\left[\mathrm{Cl}_{2} \mathrm{Ti}-\mathrm{TiCl}_{2}\right]^{*}$ in the presence of the radical $\mathrm{C}_{x} \mathrm{H}_{y}^{\bullet}$ resulting from the dissociation of pentane.

We may think then of a reaction process as

$$
\begin{aligned}
& { }^{i} \mathrm{Ti}+{ }^{j} \mathrm{TiCl}_{4} \rightarrow\left[{ }^{i} \mathrm{Ti}^{j} \mathrm{TiCl}_{4}\right]^{*} \\
& {\left[{ }^{i} \mathrm{Ti}^{j} \mathrm{TiCl}_{4}\right]^{*} \rightarrow{ }^{j} \mathrm{Ti}+{ }^{i} \mathrm{TiCl}_{4} \quad\left(\mathrm{k}_{\mathrm{D}}\right)} \\
& {\left[{ }^{i} \mathrm{Ti}^{j} \mathrm{TiCl}_{4}\right]^{*}+n \mathrm{C}_{x} \mathrm{H}_{y}^{\bullet} \rightarrow{ }^{i} \mathrm{Ti}^{j} \mathrm{TiC}_{\mathrm{nx}} \mathrm{H}_{n y}+2 \mathrm{Cl}_{2} \quad\left(\mathrm{k}_{\mathrm{Chem}}\right)}
\end{aligned}
$$

Equations 10,11 and 12 should be regarded as the simplest reactions able to produce a long lifetime complex. However, kinetic calculations ${ }^{51}$ show that a variety of titanium chlorides are formed by the dissociation of $\mathrm{TiCl}_{4}$ and, in our reaction scheme, isotopic exchange (reaction 11) can also occur between these different species. However, $\mathrm{Ti}_{2} \mathrm{Cl}_{4}$ being formed by two stable $\mathrm{TiCl}_{2}$ should have a longer lifetime likely enhancing the isotopic exchange. 
In the same spirit, the molecule $\mathrm{C}_{x} \mathrm{H}_{y}^{\bullet}$ stands for the numerous carbon radicals resulting from the dissociation of pentane and that can all participate to the reduction of the complex $\left[{ }^{i} \mathrm{Ti}^{j} \mathrm{TiCl}_{4}\right]^{*}{ }^{52-54} \mathrm{An}$ example of such a complexity is given by. ${ }^{55}$

In a plasma, the $\mathrm{Ti}$ atoms are produced by the electron impact dissociation of $\mathrm{TiCl}_{4}$ that subsequently reacts with another $\mathrm{TiCl}_{4}$ molecule, overabundant in the gas phase. Reaction (10) describes this subsequent reaction forming the $\left[{ }^{i} \mathrm{Ti}^{j} \mathrm{TiCl}_{4}\right]^{*}$ metastable molecule with the rate constant $k_{f}$ ( $f$ for formation). The superscripts $i$ and $j$ stand for isotope mass numbers.

Reaction (11) represents the spontaneous dissociation of the metastable molecule where the inverse of the $k_{D}$ ( $D$ for dissociation) stands for the lifetime of the molecule: $\tau=1 / k_{D}$. In the reaction (11), an isotope has been exchanged between $\mathrm{Ti}$ and $\mathrm{TiCl}_{4}$ but the same reaction (11) can be written with no exchange. As reported by Murphy et al, ${ }^{51} \mathrm{Ti}$ atoms condense from the gas phase as metallic nanoparticles.

Reaction (12) corresponds to the possible stabilization of $\left[{ }^{i} \mathrm{Ti}^{j} \mathrm{TiCl}_{4}\right]^{*}$ by a subsequent chemical reaction forming a solid organic product ${ }^{i} \mathrm{Ti}^{j} \mathrm{Ti}-\mathrm{C}_{x} \mathrm{H}_{y}$. Note that, according to the theoretical analysis of Marcus $^{37}$ on reaction rate constants, the isotopic exchange reactions (10) and (11) take place on the surface of the grain and not in the gas phase if the density of the reactants is too low. In this respect, the reaction (12), contrary to the formation of ozone, is not a three body reaction but a chemical reaction of the metastable molecule $\left.{ }^{i} \mathrm{Ti}^{j} \mathrm{TiCl}_{4}\right]^{*}$.

As mentioned in Section IV A, the MIF is produced by this chemical scheme because two channels are open for the subsequent reactions of the metastable molecule. We now develop a phenomenogical approach to mimic the MIF patterns that are observed in the $\delta^{m} \operatorname{Ti}(\% 0)$ vs. $m$ diagrams (Fig. 2). In this approach we assume that all isotopic processes involved in isotopic exchanges are mass-dependent.

Neglecting the possible pressure effect (as documented for ozone), the rate constant $r(12)$ for the reaction 12 is:

$$
{ }^{i j} r(12)={ }^{i j} k_{f} \times{ }^{i j} k_{\text {Chem }} \times{ }^{i j} \tau
$$

In this formalism, ${ }^{i j} \tau$ is defined for $\tau>\tau_{\min }$ and stands for the averaged lifetime of the metastable isotopomers available for the subsequent chemical reaction via the reaction 12 . For $\tau<\tau_{\text {min }}$, the metastable isotopomers spontaneously dissociate via the reaction 11 . 
In our data, isotope ratios are normalized to ${ }^{48} \mathrm{Ti}$. Hence, the rate constant ratio ${ }^{i j} f=$ ${ }^{i j} r(12) /{ }^{48-48} r(12)$ is:

$$
{ }^{i j} f=\frac{{ }^{i j} k_{f} \times{ }^{i j} k_{\mathrm{Chem}} \times{ }^{i j_{\tau}}}{{ }^{48-48} k_{f} \times{ }^{48-48} k_{\mathrm{Chem}} \times{ }^{48-48_{T_{I}}}}=\frac{{ }^{i j} k_{f}}{48-48 k_{f}} \times \frac{{ }^{i j} k_{\mathrm{Chem}}}{48-48 k_{\mathrm{Chem}}} \times \frac{{ }^{i j} j_{\tau}}{48-48_{\tau_{I}}}={ }^{i j} \alpha_{k_{f}} \times{ }^{i j} \eta
$$

with ${ }^{i j} \eta={ }^{i j} \tau /{ }^{48-48} \tau_{I}$ and ${ }^{i j} \alpha$ the MIF and MDF factors respectively (the subscript I in $\tau$ stands for indistinguishable). We assume that the $k_{f}$ and $k_{C h e m}$ ratios are mass-dependent and thus their product is also mass-dependent; hence a unique notation ${ }^{i j} \alpha_{k_{f}}$ standing for the product of the two ratios. It was shown experimentally and theoretically ${ }^{9,14}$ that ${ }^{i j} \eta$ contains also a MDF term; hence the introduction of :

$$
{ }^{i j} \eta={ }^{i j} \alpha_{\eta} \times \eta
$$

The rate constant ratio becomes:

$$
{ }^{i j} f={ }^{i j} \alpha_{k_{f}} \times{ }^{i j} \alpha_{\eta} \times \eta
$$

Under the form of equation 16, $\eta$ is (almost) constant $^{58}$ (mass-independent) and depends only on the threshold value $\tau_{\min }$ that dictates the split between the reactions 11 and 12 .

The variations of any MDF factor usually reported by the $\alpha$ notation, can be mimicked numerically with a parameter $b$ which dictates the magnitude of the $\mathrm{MDF}^{36}$ :

$$
{ }^{i j} \alpha=\left[\mu_{i-j}\right]^{b} /\left[\mu_{48-48}\right]^{b}
$$

with $\mu$ the reduced masses of the reactants.

In this phenomenological approach, for $i=j, \eta=1$ (since $\left.\eta=\tau_{I} / \tau_{I}\right)$. When $\eta=1,{ }^{i j} f$ is mass-dependent, and mass-independent for $\eta \neq 1$. $\eta$ varies with $\tau$ and $\eta=1\left(\tau=\tau_{I}\right)$ when the $\tau$ 's are integrated over the whole Boltzmann distribution; in this situation, one of the two channels is closed. Note that, contrary to the classical MDF treatment, an additional mass-dependent term ${ }^{i j} \alpha_{\eta}$ remains in ${ }^{i j} f$ even for $\eta=1$.

In the usual MDF theory, the fractionation factors are defined as the rate constant ratios of isotope exchange reactions. The relative abundances of each isotopes drop out in these ratios. This is not correct for MIF because, in a scrambled situation, all the possible reactions participate to the overall fractionation with different weights when $\eta=1$ or when $\eta \neq 1$. 
The isotopic fractionation factor is not anymore the rate constant ratio, but instead the reaction rate ratio.

In the isotopic reaction rate ratio (noted ${ }^{i j} R$ in eq. (18)), the density (or partial pressure, noted as concentration [Ti]) ratio of each isotopic species can be replaced by their relative abundance ratio (or molar fraction):

$$
\begin{aligned}
{ }^{i j} R & =\frac{\left[{ }^{i} \mathrm{Ti}\right] \times\left[{ }^{\left.{ } \mathrm{TiCl}_{4}\right]}\right.}{\left[{ }^{48} \mathrm{Ti}\right] \times\left[{ }^{48} \mathrm{TiCl}_{4}\right]} \times \frac{{ }^{i j} k_{f} \times{ }^{i j} k_{\mathrm{Chem}} \times{ }^{i j_{\tau}}}{{ }^{48-48} k_{f} \times{ }^{48-48} k_{\mathrm{Chem}} \times{ }^{48-48 \tau_{I}}} \\
& =\frac{x(i) \times x(j)}{x(48) \times x(48)} \times{ }^{i j} f
\end{aligned}
$$

The overall isotopic fractionation factor is then the sum of all the possible rate ratios ${ }^{i j} \mathrm{R}$, i.e. the sum of the contribution of all the possible isotopomers. Titanium having 5 isotopes, there are 25 possible reactions between the 5 isotopes of titanium. From equation (18) and (16), the analytical solution for the overall isotopic fractionation factor ${ }^{i-48} \alpha$ is:

$$
{ }^{i-48} \alpha=\frac{\left({ }^{i} \mathrm{Ti} /{ }^{48} \mathrm{Ti}\right)}{\left({ }^{i} \mathrm{Ti} /{ }^{48} \mathrm{Ti}\right)_{0}}={ }^{i-48} \alpha_{\mathrm{MD}} \frac{\left[1+x(i)\left(\eta^{-1}-1\right)\right]}{\left[1+x(48)\left(\eta^{-1}-1\right)\right]}
$$

$\left({ }^{i} \mathrm{Ti} /{ }^{48} \mathrm{Ti}\right)_{0}$ is the isotopic composition of the reservoir from which the products of the reaction (12) are fractionated. The MDF factors ${ }^{i j} \alpha_{k_{f}}$ and ${ }^{i j} \alpha_{\eta}$ do not appear individually in the formalism of eq. (19) but are gathered in ${ }^{i-48} \alpha_{M D}$. Under these conditions, equation (19) is exact on a large domain of variations. This equation is also correct for all the chemical elements, provided no other mass-independent effects take place during the formation of metastable molecules such as those reported in Refs. $46-48$.

The model reproduces the 4 isotopic compositions $(\approx+1250 \%)$ with a single value of the parameter $\eta=4^{50}$ (with $\alpha_{M D}=1$ i.e. with a MDF fractionation negligible compared with the observed $\delta^{m} \mathrm{Ti}=\approx+1250 \%$ ). Such a numerical result reinforces the validity of the model, and thus the MIF effect initially identified in ozone for oxygen isotopes seems as well responsible for the present data on titanium isotopes.

Note that the isotope effect is the same at all masses although the different isotopes of $\mathrm{Ti}$ have different nuclear spin values. This is an indirect evidence that the quantum interference terms between $P_{\mathrm{R}}$ and $P_{\mathrm{NR}}$ are negligible (as assumed by the MIF model ${ }^{57}$ and verified by theoretical calculations. ${ }^{64}$ ).

Note also that the isotopic abundances are approximately the same for the 4 isotopes ${ }^{46,47,49,50} \mathrm{Ti}(\approx 5 \%)$; hence the close values for the ${ }^{46,47,49,50-48} \alpha$ values. However, this is not 
the case for other chemical elements, implying that each element should exhibit its own MIF pattern. This dependency on isotopic abundances represents a test for future experiments.

\section{Isotopic constraints on the homogeneous condensation process}

As theoretically predicted by Marcus for oxygen isotopes, ${ }^{37}$ the present results confirm that the homogeneous condensation of grains promotes MIF effects. In addition, using the measured isotopic variations, it is possible to reconstruct the mechanism of grain growth.

As most other grains ${ }^{50}$, the grain reported in Table I does not fulfill an exact mass balance (i.e. a $\delta^{m} \mathrm{Ti}=0 \%$ ) with bulk $\delta^{46} \mathrm{Ti}=33.2 \%$ $\pm 4.9, \delta^{47} \mathrm{Ti}=61.1 \%$ o $\pm 4.7, \delta^{49} \mathrm{Ti}=62.9 \% \pm 4.6$, $\delta^{50} \mathrm{Ti}=92.4 \% 0 \pm 4.6$. Contrary to the grain reported in this paper, most grains do not exhibit a bulk value close to $0 \% 0 \pm 100 .{ }^{50}$ It can then be supposed that an important fraction of the grains are mechanically stripped by electron impact during their stay of the silicon wafer.

The variations in $\delta^{m} \mathrm{Ti}(\% 0)$ from the core to the surface (from positive to negative values) can be accounted for by several models i.e. distillation of a single reservoir, variations in the MIF factors or mixing models.

However, several constraints must be fulfilled by the model, namely: (i) the various correlations between $\delta^{m} \mathrm{Ti}$ and $\delta^{46} \mathrm{Ti}$ (Fig. 4) (ii) the variations between $\delta^{m} \mathrm{Ti}$ and the Ti concentration within a single grain (cf. Table I) and (iii) the maximum and minimum $\delta^{m} \mathrm{Ti}$ values reached in the core and at the surface of the grain, respectively.

Taking at face values the maximum and minimum of the measured $\delta^{m} \mathrm{Ti}$ as those of the two end-members (i.e. $+1250 \%$ and $-250 \%$ for $\delta^{46,47,49,50} \mathrm{Ti}$ ), a simple mixing model reproduces the observations (Fig. 4). In this model it is assumed that the core is progressively embedded by the growth of carbon-rich layers whose titanium isotopic compositions are around $-250 \%$. The variations in Fig. 4 are then dictated by the mass balance:

$$
0=x \delta^{m} \operatorname{Ti}(>0 \%)+(1-x) \delta^{m} \operatorname{Ti}(<0 \%)
$$

The $x$ variations mimic the various correlations between $\delta^{m} \mathrm{Ti}$ and $\delta^{46} \mathrm{Ti}$ (Fig. 4).

These variations in the $x$ value for each layer of the grain can also be calculated using the Ti concentration in the core $\left(8.32 \times 10^{2}\right)$ and in the layers $([\mathrm{Ti}])$ as:

$$
x=\left(8.32 \times 10^{2}\right) /[\mathrm{Ti}]
$$


with $8.32 \times 10^{2}$ expressed in the units of the counted ${ }^{48} \mathrm{Ti}$ ions per second (cf. Table I). As shown in Fig. 5, the calculated (20) and measured (21) $x$ values are in reasonable agreement ( $m=46$ is shown as an example).

No other models have yet been found that satisfy the data. Therefore, we conclude qualitatively that two chemical speciations of $\mathrm{Ti}$ exist in the plasma: ${ }^{48} \mathrm{Ti}$-depleted $\mathrm{TiCl}_{x}$ (or metallic $\mathrm{Ti}+\mathrm{Cl}_{2}$ ) and a ${ }^{48} \mathrm{Ti}$-rich $\mathrm{Ti}$ bound to carbon. It is the mixing of these two phases that produces the observed isotopic variations between grains, and within a single grain. As a consequence, this isotopic partition is likely dictated by the ratio of the two channels written in the reactions (11) and (12).

If correct, $\approx 20 \%$ of the metastable molecules spontaneously dissociate to form $\mathrm{TiCl}_{x}$ while $\approx 80 \%$ react with carbon $($ as $0.2 \times(+1250)+0.8 \times(-200) \approx 0 \%$ o $)$.

The suggested large $\eta$ value $(\eta=4.0)$ is still compatible with the effect involving the reaction between indistinguishable isotopes. Although it is not attempted here to calculate the $\eta$ factor explicitely through classical trajectory simulation for the present experimental conditions, the possible range of $\eta$ values can be estimated by analogy with the numerical procedures developed for ozone.

Taking eqns. 9,3 and 8

$$
\eta=\frac{\bar{\tau}_{\text {dist. }}}{\bar{\tau}_{\text {indist. }}}=\frac{y \bar{\tau}_{R}+(1-y) \bar{\tau}_{N R}}{Y \bar{\tau}_{R}+(1-Y) \bar{\tau}_{N R}}=\frac{y\left(\bar{\tau}_{R} / \bar{\tau}_{N R}\right)+(1-y)}{Y\left(\bar{\tau}_{R} / \bar{\tau}_{N R}\right)+(1-Y)}
$$

we may estimate the involved parameters. $y$, the relative contributions of exchange and non-exchange reactions, should be below 0.5 (in total there should be more NR collisions than $\mathrm{R}$, with a limit of $1 / 2$ if the minimum lifetime $\left.\tau_{\min } \rightarrow \infty\right) . \eta$ is observed to be around 4 , and the ratio of average complex lifetimes in the collision $\mathrm{Ti}+\mathrm{TiCl}_{4} \rightarrow \mathrm{Ti}_{2} \mathrm{Cl}_{4} \rightarrow \mathrm{Ti}+$ $\mathrm{TiCl}_{4}$ should be large, reflecting the difficulty of an insertion with subsequent emission of a $\mathrm{Ti}$ (not just an elastic collision). Let us take $k=\bar{\tau}_{R} / \bar{\tau}_{N R}=15$. From the three equations mentioned we obtain

$$
y(\eta, Y, k)=\frac{\eta-1}{k-1}+Y \times \eta>Y \times \eta
$$

We see immediately that $Y$, the ratio of overall collisions $R$ and $N R$, should be quite small, not larger than 0.02 , which yields $y=0.294$ which still seems quite large. Which values to take may be subjet to explicit collision simulations. 


\section{CONCLUSIONS}

The titanium isotopic fractionation observed in a plasma for the reaction $\mathrm{TiCl}_{4}+$ pentane follows the empirical rules observed for the oxygen MIF observed in ozone. Therefore, this MIF mechanism seems to describe a general behavior of isotopic exchange reactions coupled with a chemical removal of the metastable molecules involved in this isotopic exchange. This conclusion should, however, be tested with other chemical elements. It may have profound implications on models developed to account for the formation of solids during the formation of the Solar System. A theoretical treatment to reconcile the classical physics approach developed in this paper with more rigorous quantum mechanical principles remains a challenging open issue.

\section{Acknowledgments}

Funding: F.R. acknowledges support (Overheads) of the ERC Advanced Grant PaleoNanoLife (PI: F. Robert; 161764). R.T. acknowledges support from the UK Science and Technology Facilities Council (ST/P005225/1). At The University of Manchester, the NanoSIMS was funded by UK Research Partnership Investment Funding (UKRPIF) Manch-

ester RPIF Round 2, and installation of a Hyperion RF plasma ion source supported by the Henry Royce Institute for Advanced Materials. P.R. acknowledges the federation IP2CT (Sorbonne University) for computer resources. 
1 M.H. Thiemens, J.E. Heidenreich III, "The Mass-Independent Fractionation of Oxygen: A Novel Isotope Effect and its Possible Cosmochemical Implications", Science 219 (1983) 1073-1075

2 J.E. Heidenreich III, M.H. Thiemens, "A non-mass-dependent oxygen isotope effect in the production of ozone from molecular oxygen - the role of molecular symmetry in isotope chemistry", J.Chem.Phys 84 (1986) 2129-2136

3 M.H. Thiemens, "Introduction to Chemistry and Applications in Nature of Mass Indepedendent Isotope Effects Special Feature", PNAS 110 (2013) 17631-17637

4 S.M. Anderson, J. Morton, K. Mauersberger, "Laboratory measurements of ozone isotopomers by tunable diode-laser absorption-spectroscopy", Chem.Phys.Lett. 156 (1989) 175-180

5 M.H. Thiemens, T. Jackson, "Pressure dependency for heavy isotope enhancement in ozone formation", Geophys.Res.Lett. 17 (1990) 717-719

6 J. Morton, J. Barnes, B. Schueler, K. Mauersberger, "Laboratory studies of heavy ozone", J.Geophys.Res.-Atm. 95 (1990) 901-907

7 D. Krankowsky, K. Mauersberger, "Atmospheric chemistry - Heavy ozone - A difficult puzzle to solve", Science 274 (1996) 1324-1325

8 K. Mauersberger, B. Erbacher, D. Krankowsky, J. Guenther, R. Nickel, "Ozone isotope enrichment: Isotopomer-specific rate coefficients", Science 283 (1999) 370-372

9 C. Janssen, J. Guenther, K. Mauersberger, D. Krankowsky, "Kinetic origin of the ozone isotope effect: a critical analysis of enrichments and rate coefficients", Phys.Chem.Chem.Phys. 3 (2001) $4718-4721$

10 Y.Q. Gao, R.A. Marcus, "Strange and unconventional isotope effects in ozone formation", Science 293 (2001) 259

11 D. Babikov, R.B. Walker, R.T. Pack, "A quantum symmetry preserving semiclassical method", J.Chem.Phys. 117 (2002) 8613-8622

12 Y.Q. Gao, R.A. Marcus, "On the theory of the strange and unconventional isotopic effects in ozone formation", J.Chem.Phys. 116 (2002) 137-154

13 R. Schinke, P. Fleurat-Lessard, S.Y. Grebenshchikov, "Isotope dependence of the lifetime of ozone complexes formed in O+O 2 collisions", Phys.Chem.Chem.Phys. 5 (2003) 1966-1969 DOI: 10.1039/b301354e.

14 R. Schinke, P. Fleurat-Lessard, "The effect of zero-point energy differences on the isotope dependence of the formation of ozone: a classical trajectory study", J.Chem.Phys. 122 (2005) 
094317 DOI: 10.1063/1.1860011

15 M.V. Ivanov, D. Babikov, "On molecular origin of mass-independent fractionation of oxygen isotopes in the ozone forming recombination reaction", Proc.Nat.Acad.Sci. 110 (2013) 1770817713

16 A. Teplukin, I. Gayday, D. Babikov, "Several levels of theory for description of isotope effects in ozone: Effect of resonance lifetimes and channel couplings", J.Chem.Phys. 149 (2018) 164302 doi.org/10.1063/1.5042590.

17 S. Ndengué, S. Madronich, F. Gatti, H-D. Meyer, O. Motapon, R. Jost, "Ozone photolysis: Strong isotopologue/isotopomer selectivity in the stratosphere", J.Geophys.Res. Atmos. 119 (2014) 4286-4302, doi:10.1002/2013JD020033

18 S. Ndengué, R. Schinke, F. Gatti, H-D. Meyer,R. Jost, "Ozone Photodissociation: Isotopic and Electronic Branching Ratios for Symmetric and Asymmetric Isotopologues", J. Phys. Chem. A 116 (2012) 12271-12270, dx.doi.org/10.1021/jp307195v

19 S. Ndengué, R. Schinke, F. Gatti, H-D. Meyer,R. Jost, "Comparison of the Huggins Band for Six Ozone Isotopologues: Vibrational Levels and Absorption Cross Section", J. Phys. Chem. A 116 (2012) 12260-12270, dx.doi.org/10.1021/jp3064382

20 F. Robert, L. Baraut-Guinet, P. Cartigny, P. Reinhardt, "An experimental test for the massindependent isotopic fractionation mechanism proposed for ozone", Chem.Phys. 523 (2019) $191-197$

21 R.N. Clayton, L. Grossman, T.K. Mayeda, "A component of primitive nuclear composition in carbonaceous meteorites", Science 182 (1973) 485-488

22 D. Ebel, "Condensation of Rocky Material in Astrophysical Environments", MESS II (2006) $253-280$

23 T.R. Ireland, E.K. Zinner, S. Amari, "Isotopically anomalous Ti in Presolar SiC from the Murchison meteorite", Astrophys.J. 376 (1991) L53-L56

24 P. Hoppe, S. Amari, E. Zinner, T. Ireland, R.S. Lewis, "Carbon, nitrogen, magnesium, silicon and titanium isotopic compositions of single interstellar silicon carbide grains from the Murchison carbonaceous chondrite.", Astrophys.J. 430 (1994) 870-890

25 E. Zinner, "Stellar nucleosynthesis and the isotopic composition of presolar grains from primitive meteorites", Annu.Rev.Earth Planet.Sci. 26, (1998) 147-188

26 C.M. Alexander, L.R. Nittler, E. Zinner, T. Ireland, R.S. Lewis, "The galactic evolution of Si, 
Ti, and O isotopic ratios.", Astrophys.J. 519 (1999) 222-235

27 P. Hoppe, E. Zinner, "Presolar dust grains from meteorites and their stellar sources.", J. Geophys. Res. 105 (2000) 10371-10385

28 E. Zinner, S. Amari, R. Guinness, C. Jennings, F. Aaron, A.N. Mertz, R. Gallino, P. Hoppe, M. Lugaro, L.R. Nitler, R. Lewis, "PreNanoSIMS isotopic analysis of small presolar grains: Search for Si3N4 grains from AGB stars and $\mathrm{Al}$ and $\mathrm{Ti}$ isotopic compositions of rare presolar SiC grains.", Geochim. Cosmochim. Acta 71 (2007) 4786-4813

29 F.R. Niederer, D.A. Papanastassiou, G.J. Wasserburg, "Absolute isotopic abundances of Ti in meteorites", Geochim.Cosmochim.Acta 49 (1995) 835-851

30 A. Trinquier, T. Elliott, D. Ulfbeck, C. Coath, A.N. Krot, M. Bizzarro, "Origin of Nucleosynthetic Isotope Heterogeneity in the Solar Protoplanetary Disk", Science 324 (2009) 374-376

31 I. Leya, M. Schönbächler, U. Wiechert, U. Krähenbühl, A. Halliday, "Titanium isotopes and the radial heterogeneity of the solar system", Earth.Planet.Sci.Lett. 266 (2008) 233-244

32 M. Schiller, M. Bizzarro, V.A. Fernandes, "Isotopic evolution of the protoplanetary disk and the building blocks of Earth and the Moon", Nature 555 (2018) 507-510

33 N. Dauphas, E.A. Schauble, "Mass Fractionation Laws, Mass-Independent Effects, and Isotopic Anomalies", Annu.Rev.Earth Planet.Sci. 44 (2016) 709-783

34 K. Lodders, "Titanium and Vanadium chemistry in low-mass Dwarf stars", Astrophys.J. $\mathbf{5 7 7}$ (2002) 974-985

35 J.L. Birck, "An Overview of Isotopic Anomalies in Extraterrestrial Materials and Their Nucleosynthetic Heritage", Rev.Miner., Geochem. 55 (2004) 25-64

36 F. Robert, "The common property of isotopic anomalies in meteorites", Astron.Astrophys. 415 (200) 1167-1176

37 R.A. Marcus, "Mass-independent isotope effect in the earliest processed solids in the solar system: A chemical mechanism", J.Chem.Phys. 121 (2004) 8201-8211

H.C. Urey, "The thermodynamic properties of isotopic substances", J.Am.Chem.Soc. (1947) $562-581$

39 J. Bigeleisen, "The relative reaction velocities of isotopic molecules", J.Chem.Phys. 17 (1949) $675-678$

40 E.D. Young, A. Galy, H. Nagahara, "Kinetic and equilibrium mass-dependent isotope fractionation laws in nature and their geochemical and cosmochemical significance", 
Geochim.Cosmochim.Acta 66 (2002) 1095-1104

41 M.F. Miller, "Isotopic fractionation and the quantification of ${ }^{17} \mathrm{O}$ anomalies in the oxygen three-isotope system: an appraisal and geochemical significance", Geochim.Cosmochim.Acta 66 (2002) 1881-1889

42 M.H. Thiemens, "Atmosphere science - Mass-independent isotope effects in planetary atmospheres and the early solar system", Science 283 (1999) 341-345

43 M.H. Thiemens, M. Lin, "Use of Isotope Effects to Understand the Present and Past of the Atmosphere and Climate and Track the Origin of Life", Angew.Chem.Int.Ed. 58 (2019) 68266844

44 S. Chakraborty, B.H. Muskatel, T.L. Jackson, M. Ahmed, R.D. Levine, M.H. Thiemens, "Massive isotopic effect in vacuum UV photodissociation of $\mathrm{N}_{2}$ and implications for meteorite data", Proc.Nat.Acad.Sci. 111 (2014) 14704-14709

45 F. Robert, S. Derenne, G. Lombardi, K. Hassouni, A. Michau, P. Reinhardt, R. Duhamel, A. Gonzalez, K. Biron, "Hydrogen isotope fractionation in methane plasma", Proc.Nat.Acad.Sci. 114 (2017) 870-874

46 L.L. Yasina, A.L. Buchachenko, "Magnetic isotope effect and oxygen isotope selection in oxidation chain reactions", Chem.Phys. 146 (1990) 225-229

47 A.L. Buchachenko, "Magnetic Isotope Effect: Nuclear Spin Control of Chemical Reactions,", J.Phys.Chem.A, 105 (2001) 996-1011

48 A.L. Buchachenko, "Magnetic isotopes as a means to elucidate Earth and environmental chemistry", Russ.Chem.Rev. 87 (2018) 727-740

49 J. Farquhar, H.M. Bao, M. Thiemens, "Atmospheric Influence of Earth's Earliest Sulfur Cycle", Science 289 (2000) 756-759

50 F. Robert, R. Tartese, G. Lombardi,P. Reinhardt, M. Roskosz, B. Doisneau, Z. Deng, M. Chaussidon, "Mass-independent fractionation of titanium isotopes and its cosmochemical implications", Nat. Astron. (2020) 1-7 DOI: org/10.1038/s41550-020-1043-1

51 A.B. Murphy, "Formation of titanium nanoparticles from a titanium tetrachloride plasma", J.Phys.D: Appl.Phys. 37 (2004) 2841

52 G. Lombardi, K. Hassouni, G.D. Stancu, L. Mechold, J. Ropcke , A. Gicquel, "Study of an $\mathrm{H}_{2} / \mathrm{CH}_{4}$ moderate pressure microwave plasma used for diamond deposition: modelling and IR tuneable diode laser diagnostic", Plasma Sources Sci. Technol. 14 (2005) 440-450 
doi:10.1088/0963-0252/14/3/005

53 G. Lombardi, "Diagnostics spectroscopiques d'espèces carbonées et modélisation physicochimique de plasmas micro-ondes dans les mélanges $\mathrm{H}_{2} / \mathrm{CH}_{4}$ et $\mathrm{Ar} / \mathrm{H}_{2} / \mathrm{CH}_{4}$ utilisés pour le dépôt de diamant", Thesis Univ. Paris XI, Orsay (2003)

54 F. Mohasseb, "Etude d'un procédé de dépôt de films de diamant nanocristallin par des plasmas micro-ondes de $\mathrm{CH}_{4} / \mathrm{H}_{2} / \mathrm{Ar}$ ", Thesis Univ. Paris XIII Villetaneuse (2004)

55 M. Scapinello, E. Delikonstantis, G.D. Stefanidis, "A study on the reaction mechanism of nonoxidative methane coupling in a nanosecond pulsed discharge reactor using isotope analysis", Chem.Engin.J 360 (2019) 64-74 https://doi.org/10.1016/j.cej.2018.11.161

56 L. Lin, S.A. Starostin, Q. Wang, V. Hessel, "An atmospheric pressure microplasma process for continuous synthesis of titanium nitride nanoparticles", Chem.Engin.J. 321 (2017) 447-457

57 P. Reinhardt, F. Robert, "Mass-independent isotope fractionation in ozone", Earth and Planet.Sci.Lett. 368 (2013) 195-203

58 P. Reinhardt, F. Robert, "On the mass independent isotopic fractionation in ozone", Chem.Phys. 513 (2018) 287-294

59 A. Lacoste., T. Lagarde, S. Bechu, Y. Arnal, J. Pelletier, "Multi-dipolar plasmas for uniform processing: physics, design and performance", Plasma Sources Sci.Technol. 11 (2002) 407-412

60 A. Lieberman, A.J. Lichtenberg, "Principles of Plasma Discharges and Materials Processing", John Wiley and Sons, New York, (2005)

61 K. Biron, S. Derenne, F. Robert, J.N. Rouzaud, "Toward experimental synthesis of the chondritic insoluble organic matter", Meteor.Plan.Sci. 50 (2015) 1408-1422

62 S. Derenne, F. Robert, "Model of molecular structure of the Insoluble Organic Matter isolated from Murchison meteorite", Meteor.Plan.Sci. 45 (2010) 1461-1475

63 Z. Deng, M. Chaussidon: personal communication, Institut de Physique du Globe, Paris, France

64 T.R. Rao, G. Guillon, S. Mahapatra, P. Honvault, "Huge Quantum Symmetry Effect in the O $+\mathrm{O}_{2}$ Exchange Reaction", J.Phys.Chem.Lett. 6 (2015) 633-636

65 For completeness we give as well $P_{\mathrm{R}}=\int_{0}^{\tau_{\min }} f_{\mathrm{R}} d \tau / \int_{0}^{\infty} f_{\mathrm{R}} d \tau>0$. 


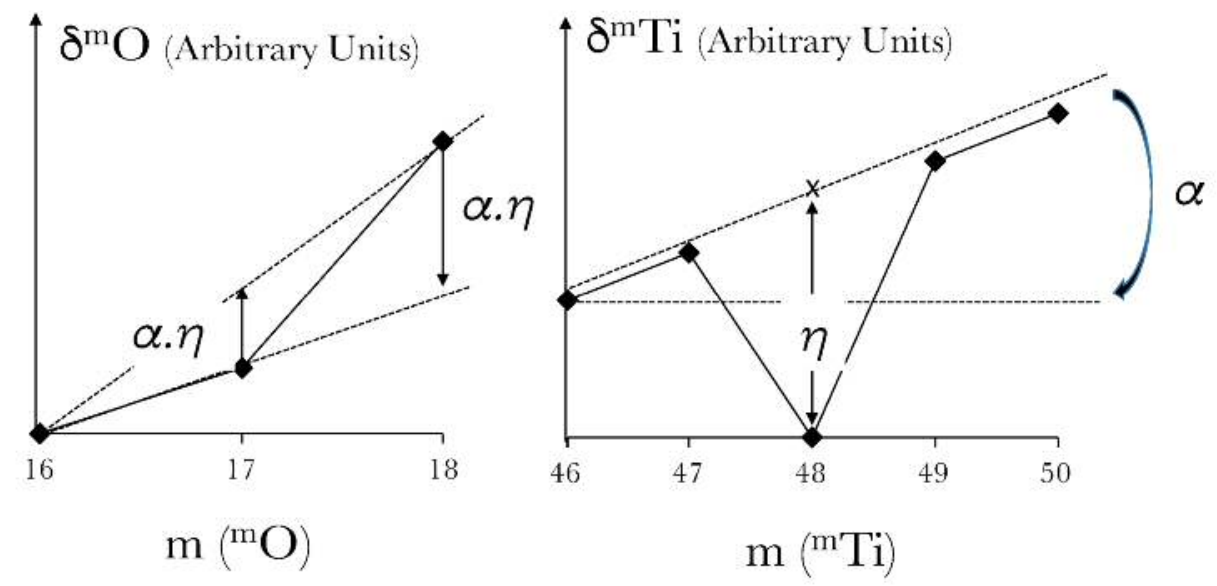

FIG. 1: Schematic example showing that in a 3 isotope system (oxygen as an example), it is not possible to distinguish between the MDF and MIF contributions ( $\alpha$ and $\eta$, respectively) in the overall isotope effect. This uncertainty is resolved for $n>3$ isotope systems (titanium as an example). 


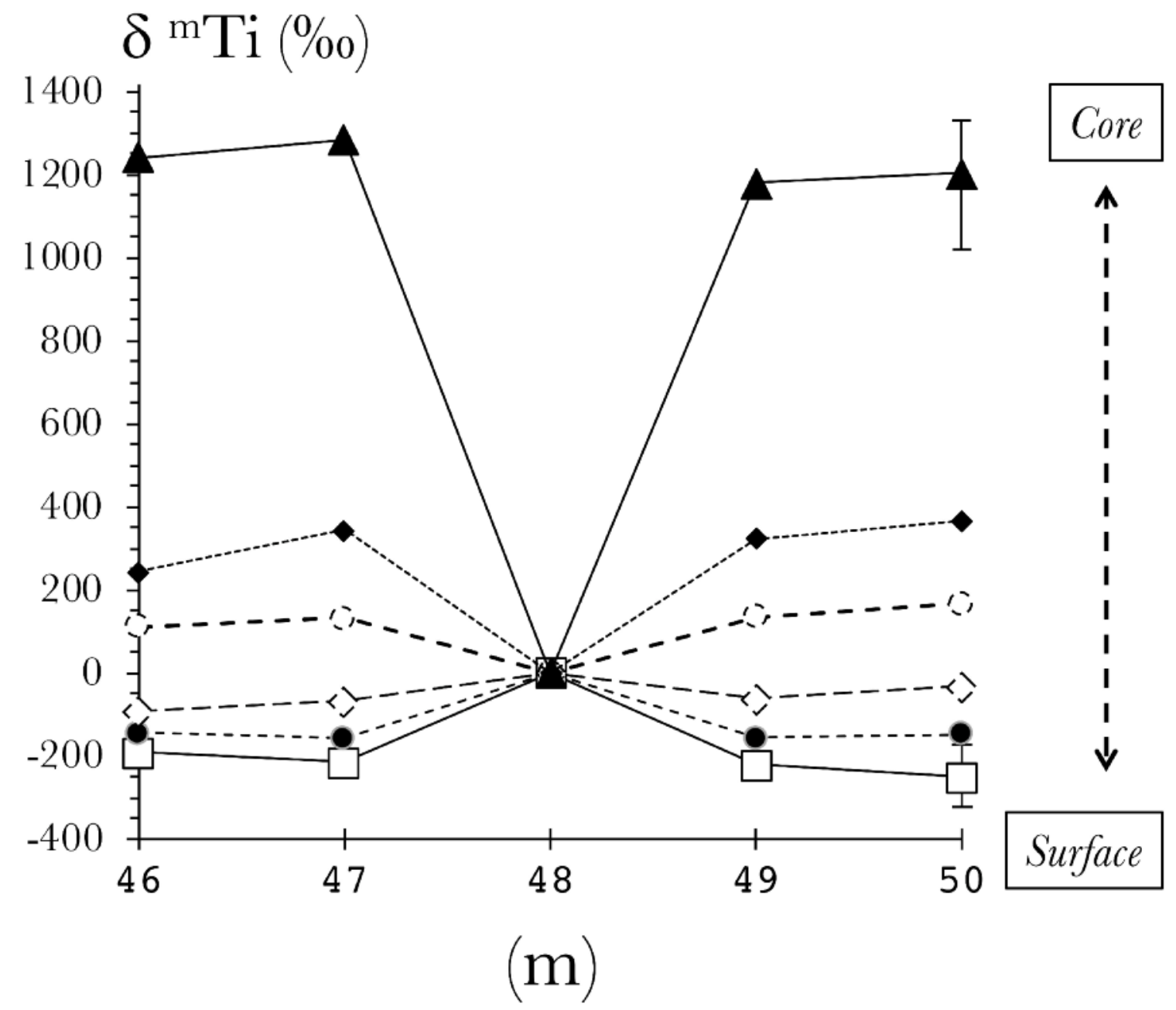

FIG. 2: : Distribution of the titanium isotope ratios ${ }^{m} \mathrm{Ti} /{ }^{48} \mathrm{Ti}$ in an organic grain deposited from a $\mathrm{TiCl}_{4} /$ pentane plasma. Units are $\delta^{m} \mathrm{Ti}(\% 0)$ with $\mathrm{m}$ standing for 46, 47, 48, 49, and 50 mass units. Error bars $( \pm 1 \sigma)$ are indicated for the highest and lowest isotopic patterns where they are larger than the symbol size used for the data. On these two patterns, error bars are approximately the same for all the masses (cf. Table I for more precise values on error bars). The $\delta^{m} \mathrm{Ti}(\%$ o $)$ values measured in the same domain of concentration are connected by broken lines (solid or dashed). These domains of concentrations correspond to a spatial distribution in the grain with the lowest concentrations associated with the higest $\delta^{m} \mathrm{Ti}(\% 0)$ in the core and vice versa for the surface. 


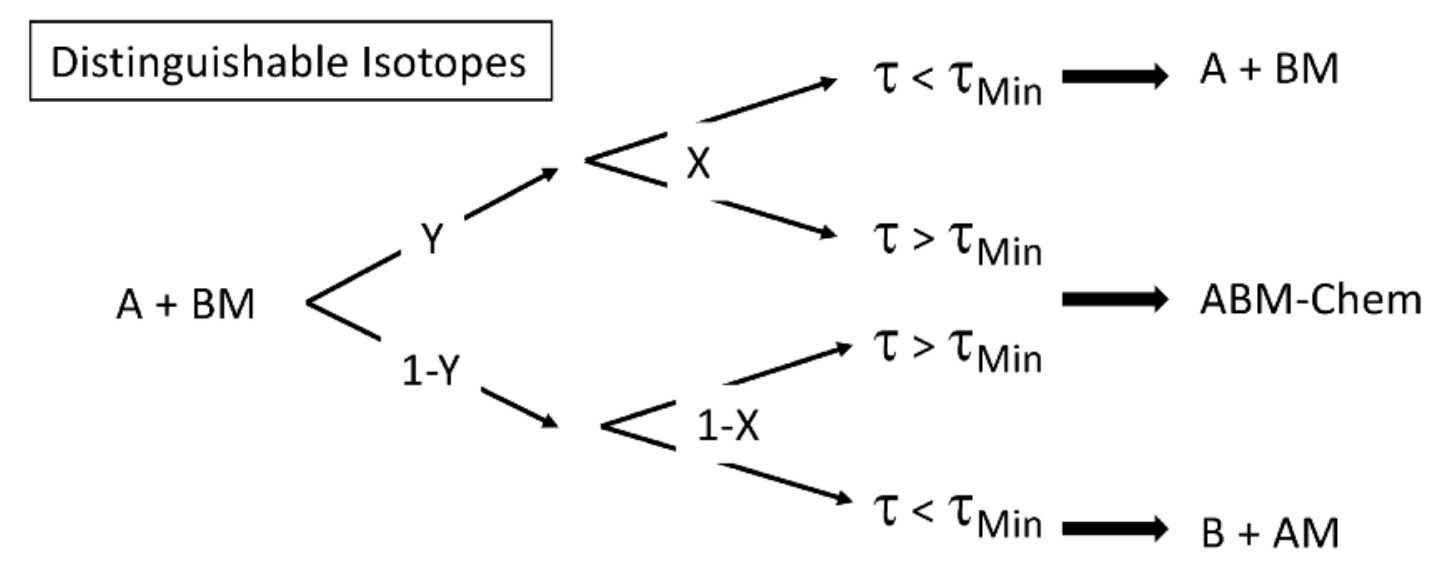

Indistinguishable Isotopes

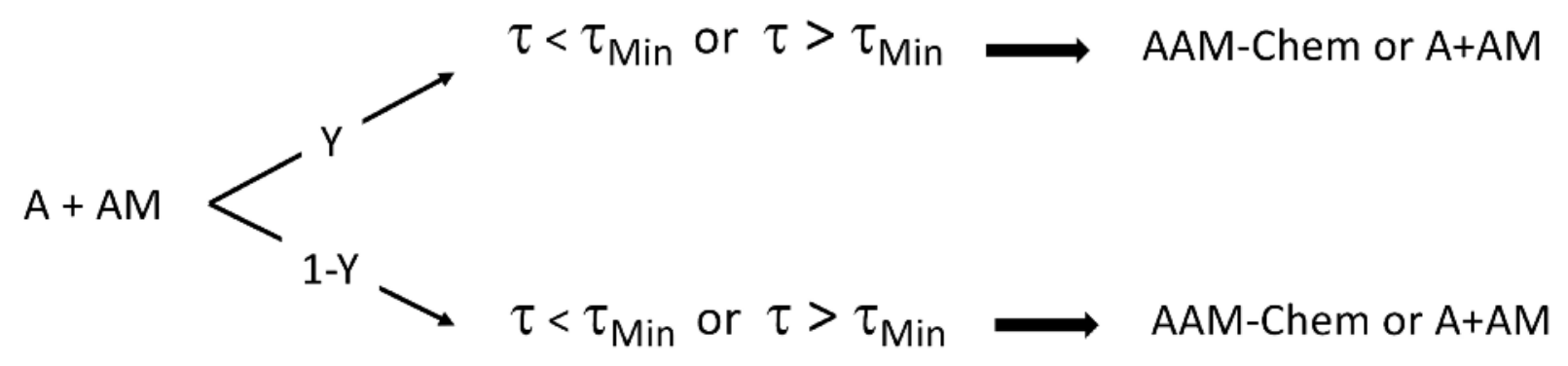

FIG. 3: The principle for the calculation of the isotopic fractionation involved in the formation of the intermediate metastable molecules $[\mathrm{ABM}]^{*}(\mathrm{~A}+\mathrm{BM})$ or $[\mathrm{AAM}]^{*}(\mathrm{~A}+\mathrm{AM})$ is schematically shown in the figure. A and B designates two isotopes of the same chemical element and $\mathrm{M}$ is a chemical bound. "Chem" designates a chemical reactant with $[\mathrm{ABM}]^{*}$ or $[\mathrm{AAM}]^{*}$. When isotopes are indistinguishable, one cannot decide if the incident $\mathrm{A}$ is in the chemical product AAM or is emitted as A by the spontaneous dissociation of $[\mathrm{AAM}]^{*}$. 


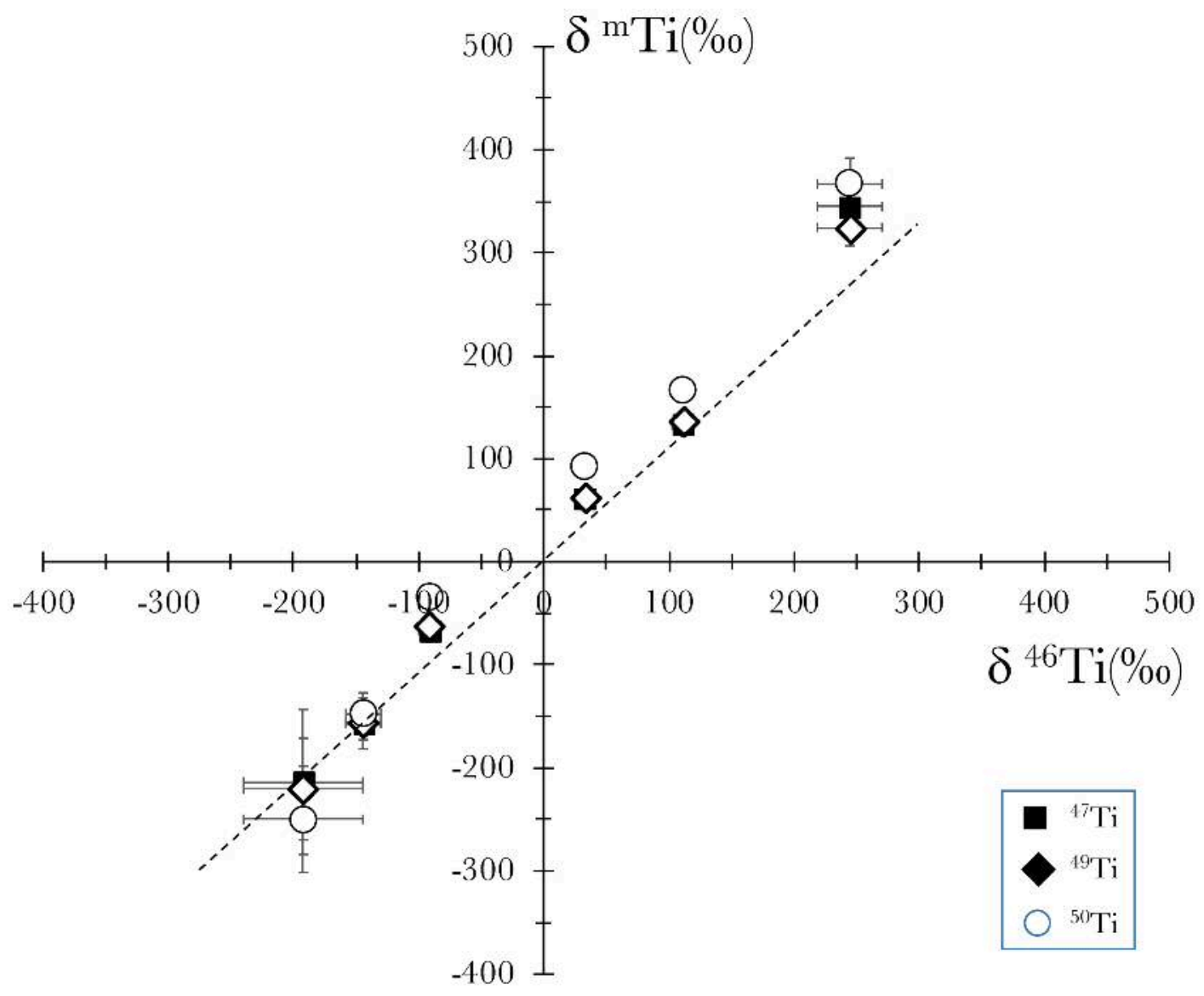

FIG. 4: $\delta^{m} \operatorname{Ti}(\% 0)$ versus $\delta^{46} \mathrm{Ti}(\% 0)$ for the different regions of the grain (m standing for 47,49 or 50). The dashed line is the calculated mixing line between two end members having $\delta^{m} \operatorname{Ti}(\% 0)=$ $+1250 \%$ and $\delta^{m} \mathrm{Ti}(\% 0)=-250 \%$, corresponding to the maximum and minimum measured $\delta^{m} \mathrm{Ti}$ values. 


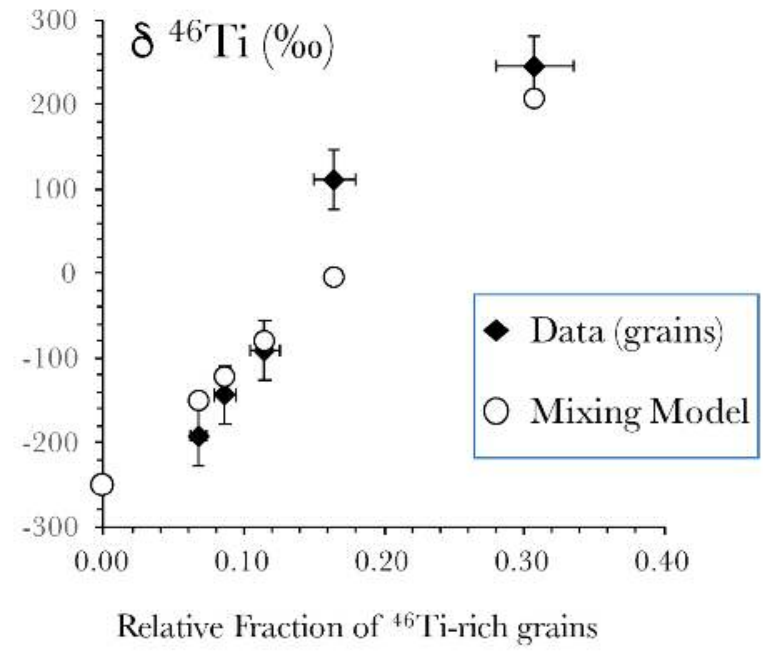

FIG. 5: The calculated and measured relative mixing fractions of two end members having $\delta^{m} \mathrm{Ti}=$ $+1250 \%$ and $\delta^{m} \mathrm{Ti}=-250 \%$ are compared. The progressive decrease in $\delta^{46} \mathrm{Ti}(\% 0)$ from the core to the surface of the grain is caused by the progressive addition of ${ }^{48} \mathrm{Ti}$-depleted organic $\mathrm{Ti}$ in a ${ }^{48}$ Ti-rich Ti phase. 


\begin{tabular}{rcccccccccccc}
${ }^{12} \mathrm{C}$ & ${ }^{35} \mathrm{Cl}$ & ${ }^{48} \mathrm{Ti}$ & $\delta^{46} \mathrm{Ti}$ & $\pm 1 \sigma$ & $\delta^{47} \mathrm{Ti}$ & $\pm 1 \sigma$ & $\delta^{48} \mathrm{Ti}$ & $\delta^{49} \mathrm{Ti}$ & $\pm 1 \sigma$ & $\delta^{50} \mathrm{Ti}$ & $\pm 1 \sigma$ \\
\hline Surface $8.24 \mathrm{E}+00$ & $5.49 \mathrm{E}+00$ & $1.24 \mathrm{E}+04$ & -192.1 & 48 & -213.6 & 70 & 0.0 & -220.6 & 49 & -249.9 & 51 \\
$4.19 \mathrm{E}+00$ & $1.47 \mathrm{E}+00$ & $9.62 \mathrm{E}+03$ & -144.0 & 14 & -156.7 & 25 & 0.0 & -156.2 & 17 & -147.0 & 20 \\
$4.16 \mathrm{E}+00$ & $7.80 \mathrm{E}-01$ & $7.24 \mathrm{E}+03$ & -91.6 & 8 & -66.8 & 6 & 0.0 & -62.3 & 8 & -33.0 & 8 \\
$3.32 \mathrm{E}+00$ & $7.40 \mathrm{E}-01$ & $5.07 \mathrm{E}+03$ & 111.2 & 9 & 133.1 & 6 & 0.0 & 136.0 & 7 & 167.9 & 7 \\
$1.90 \mathrm{E}+00$ & $9.10 \mathrm{E}-01$ & $2.71 \mathrm{E}+03$ & 244.5 & 26 & 344.8 & 16 & 0.0 & 324.5 & 18 & 366.8 & 25 \\
Core $6.50 \mathrm{E}-01$ & $2.59 \mathrm{E}+00$ & $8.32 \mathrm{E}+02$ & 1241.0 & 143 & 1284.4 & 154 & 0.0 & 1180.5 & 176 & 1204.3 & 180
\end{tabular}

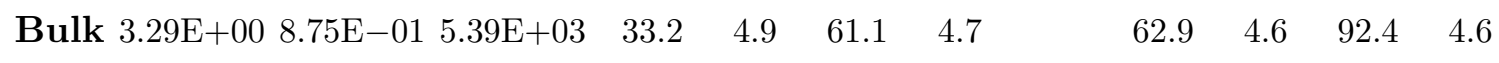

TABLE I: Distribution of $\delta^{m} \mathrm{Ti}(\% 0)$ and of the $\mathrm{C}, \mathrm{Cl}$ and $\mathrm{Ti}$ relative concentrations expressed as the number of ions counted per second in an $\approx 2 \mu \mathrm{m}$ diameter grain (the rastered NanoSims image is a $3 \times 3 \mu \mathrm{m}$ square). 